Forensic science

\section{DNA fingerprinting in matters of family and crime}

\author{
from Barbara E. Dodd
}

IT HAS long been the ambition of the forensic scientist to be able to identify the origin of blood and body-fluid stains with the same degree of certainty as fingerprints. And the ability to settle cases of doubtful paternity with absolute certainty in every case would be equally welcome. The arrival of DNA fingerprinting - particularly as developed by Alec Jeffreys and colleagues at Leicester University ${ }^{1.3}$. whose latest paper is on page 577 of this issue $^{\downarrow}$ - is a big step towards the forensic scientist's goal in both areas.

As so often happens, the technique has arisen from research that was not aimed specifically at solving practical problems. Jeffreys had been working on the short 'minisatellite' sequence of DNA in an intron of the human myoglobin gene. Using the now familiar methods of Southern blotting and DNA hybridization he found that the myoglobin minisatellite detected other human minisatellites, some of which are highly polymorphic. The common features of these minisatellites have been identified by sequencing, and cloned DNA probes, based on tandem repeats of the core sequences, have been used to detect simultaneously several highly variable genetic loci in the human genome. It is this extreme variability in the pattern of minisatellites detected by the probes, together with the stable inheritance in the usual mendelian manner of an individual's pattern. that is the basis of DNA fingerprinting.

In this issue of Nature. Jeffreys with P. Gill and D.J. Werrett of the Home Office Forensic Science Service report promising progress in applying DNA fingerprinting to blood stains. semen stains and hair roots, showing that DNA fingerprints obtained from these sources are always identical to those of the individuals from whom the material originated. Especially rewarding are the results of DNA fingerprints of sperm nuclei and their potential for the identification of rapists. There are conventional genetic markers in semen and semen stains are frequently contaminated with vaginal fluid, so that the origin of any markers present is difficult or wellnigh impossible to trace. Gill et al. have managed to isolate sperm nuclei free from vaginal contamination and have obtained a DNA fingerprint that is the same as the donor of the sperm. Thus it should be possible to match a DNA fingerprint of sperm from, for example, a stain on a victim's clothing with that of blood or sperm from a suspect rapist. A chance match is virtuaily eliminated because its probability is calculated to be of the order of $3 \times 10^{-11}$, or even less if more than one

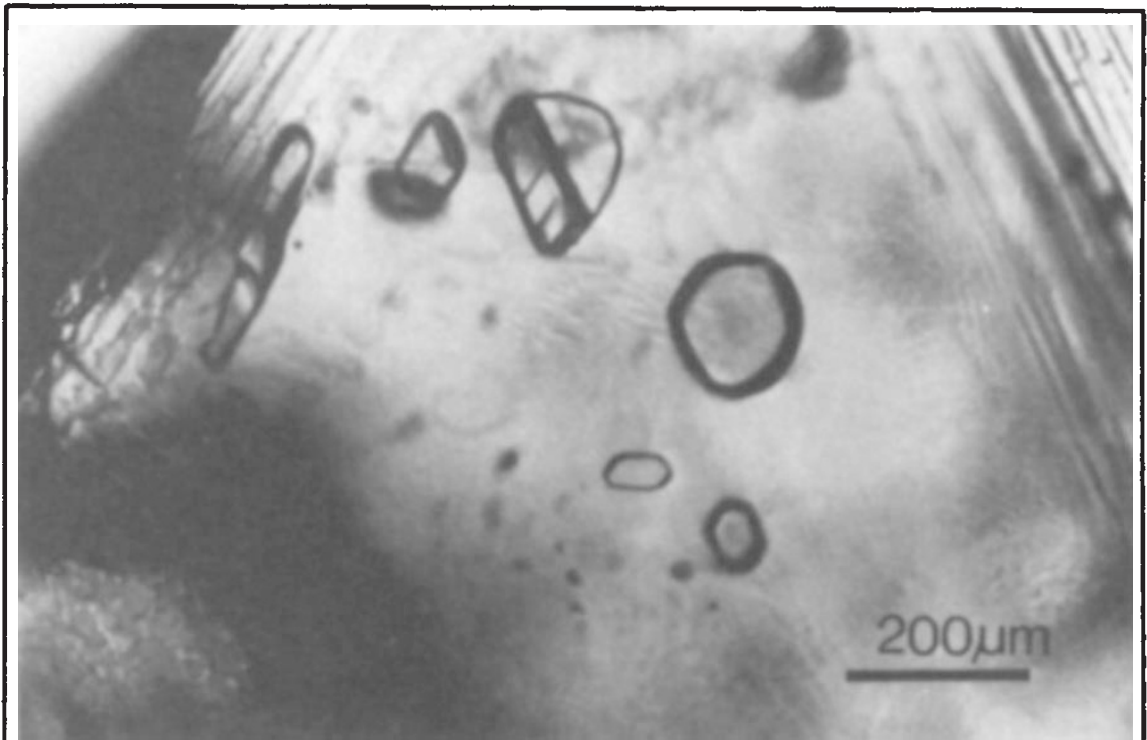

\title{
Unique garnets in diamonds
}

Enlarged view of a diamond, from the Monastery Mine kimberlite pipe in South Africa, that contains two garnet inclusions (on the right-hand side, with dark shadows surrounding them) and four jadeiitic clinopyroxene inclusions. The garnets are the first of natural occurrence to contain pyroxene in solid solution, which indicates an unusually deep origin for the diamonds. This discovery and its implications for mantle structure are described by R.O. Moore and J.J. Gurney on page 553 of this issue.

probe is used. The technique, however. has yet to be tested and assessed for application in actual casework. How easily DNA fingerprinting can be assimilated in a routine crime laboratory remains to be established.

Other work is in progress on the feasib. ility of using DNA polymorphisms in the examination of blood and semen stains. M. Baird and colleagues of Lifecode Corp.. New York reported at the 11 th International Congress of the Society for Forensic Haematogenetics in Copenhagen last August. They have used probes that recognize two highly polymorphic DNA sequences to show that DNA recovered from blood stains up to three years old can be used for identification purposes and that the DNA fingerprints of sperm recovered from female volunteers after sexual activity, when freed of female cells, is identical to that of the male partner's sperm.

The numerous blood-group polymorphisms that are currently applied to cases of doubtful parentage (usually doubtful paternity) already go far towards excluding every man wrongly named as father of a child. Exclusion of paternity is established by showing the absence in the putative father of one or more blood-group gene products, which, in the child, are seen to be paternally inherited. A range of polymorphic systems are investigated independently of each other by relatively simple procedures in which the gene products are disclosed by agglutination, cytotoxicity tests or some form of electrophoresis. The table shows how a combination of polymorphisms can approach the ability to exclude all false fathers. Moreover, the calculated probability of paternity for unexcluded men, virtually all of whom will be true fathers, is likely to be significantly in favour of their paternity.

Even so, DNA fingerprinting with the probes developed by Jeffreys has the potential to exceed the efficiency of the conventional systems because there are good grounds for anticipating that definitive answers, not only those excluding paternity but also for pinpointing the true father, will be obtained in every case. But it is in resolving problems of family relationships in which putative parents are closely related to each other that DNA fingerprinting has particular advantages over presently used systems. This has already been demonstrated by Jeffreys $e t$ $a l .^{3} ;$ the problem was that of a Ghanaian boy who was refused entry into Britain because the authorities were not satisfied that the woman claiming him as her son was in fact his mother. Analysis of a range of systems similar to those in the table showed that the alleged mother and son were almost certainly related (probability of non-relationship 0.01 ) but the conventional tests were not capable of determining whether the woman was the boy's mother or aunt. DNA fingerprinting established that the mother-son rel- 